\title{
Coulisses
}

Revue de théâtre

13 | Hiver 1996

Varia

\section{Un théâtre pour lire la société}

\section{André Parrend}

\section{OpenEdition}

Journals

Édition électronique

URL : http://journals.openedition.org/coulisses/4197

DOI : $10.4000 /$ coulisses.4197

ISSN : 2546-9460

\section{Éditeur}

Presses universitaires de Franche-Comté

\section{Édition imprimée}

Date de publication : 1 janvier 1996

Pagination : 58

ISSN : 1150-594X

\section{Référence électronique}

André Parrend, «Un théâtre pour lire la société », Coulisses [En ligne], 13 | Hiver 1996, mis en ligne le 15 mars 2019, consulté le 04 octobre 2020. URL : http://journals.openedition.org/coulisses/4197 ; DOI : https://doi.org/10.4000/coulisses.4197

Ce document a été généré automatiquement le 4 octobre 2020.

Coulisses 


\title{
Un théâtre pour lire la société
}

\author{
André Parrend
}

1 Cette pièce m'a passionné. Où est $1 \mathrm{a}$ part d'Octave Mirbeau dans cet intérêt, où est celle du metteur en scène? L'osmose a été si parfaite qu'il est difficile de rendre à César ce qui lui appartient, et c'est un grand compliment que j'adresse là à celui qui l'a mise en forme.

2 Elle m'a tout d'abord passionné par son ressort fondamental :

la pièce est la relation du développement d'une situation de crise, révélatrice des caractères, des pratiques, de l'idéologie d'une classe. De nombreuses pièces de théâtre bien faites utilisent ce ressort. Une épidémie apparaît, que le groupe social refuse, car elle concerne, dit-il, les autres, pas lui. Le groupe résiste, s'arc-boute, fait le gros dos, renvoie la responsabilité à autrui, refuse d'examiner la question, de se sentir concerné, de prendre des décisions. Dans un deuxième temps, le mal atteint le groupe lui-même, le secoue, le désorganise, le met en danger d'éclatement; on frise la catastrophe. Mais l'instinct est le plus fort: la classe se ressoude et on finit par le Champagne.

$\mathrm{Au}$ cours de cette traversée du désert, toute la gamme de l'idéologie peut alors être développée : égoïsme, amour de l'argent, mépris des autres, veulerie, etc.

3 La pièce m'a passionné ensuite par sa construction :

ici sont traités simultanément, et la mise en scène, par sa qualité, le fait apparaître à tout instant et même l'enrichit, un personnage collectif, la bourgeoisie, et des personnages individuels, les bourgeois, le premier renvoyant au second en permanence (cf. l'image clin d'œil du metteur en scène qui présente les comparses recomposant la sculpture de Rude, La Marseillaise). C'est chaque bourgeois qui construit le personnage collectif, c'est le personnage collectif qui détermine chaque bourgeois.

4 C'est enfin son fonctionnement qui m'a intéressé, un fonctionnement qui interdit au public de s'identifier :

- et dans la pièce, par l'outrance même du langage qui atteint son apogée dans la scène où le bourgeois s'auto-décrit, s'autodétruit en se racontant.

- et dans la mise en scène, par l'outrance du traitement des costumes, des attitudes, de la manière de parler, du jeu.

Mirbeau, avant Brecht, savait faire travailler le public avec sa tête. 
5 Interrogeons-nous, pour terminer, sur le statut que le metteur en scène attribue au public présent dans la salle : statut de connivence au début de la pièce, le public fait partie des amis admis à assister à la réunion du conseil, on condescend même à lui faire des confidences. Statut d'ennemi ensuite : le public, c'est l'autre, qui amène les ennuis, génère l'épidémie, met le groupe en danger.

6 Ce public, le troisième partenaire. Avec lui, le tiercé théâtral parfait a fonctionné : grâce au Théâtre Universitaire, l'auteur, le metteur en scène et le public se sont vraiment rencontrés au travers de cette réalisation. 